\title{
AN ENVIRONMENTAL WATCH SYSTEM FOR THE ANDEAN COUNTRIES El Observatorio Andino
}

\author{
by Ángel G. Muñoz, Patricio lópez, Ramón Velásquez, luis Monterrey, Gloria león, Franklyn Ruiz, \\ Cristina Recalde, Jaime Cadena, Raúl Mejía, Marcos Paredes, Juan Bazo, Carmen Reyes, \\ Gualberto Carrasco, Yaruska Castellón, Claudia Villarroel, Juan Quintana, and Avel Urdaneta
}

\section{A regional network in experimental mode over the last two years monitors environmental variables and develops scientifically based forecasts with easy-to-use oceanographic, meteo- rological, and hydrological products for decision makers in the six collaborating countries.}

T he Andean countries are located in the western and northern regions of South America. Most of them lie in the tropical strip, where complex atmospheric dynamics and the lack of a comprehensive understanding of mesoscale and microphysical phenomena lead to difficult forecasting challenges. More than 7,000 km long, typically $200 \mathrm{~km}$ wide, and with about a 4,000-m average height, the Andean Mountain chain includes complex topographic features, with substantial repercussions on the meteorological and climatological behavior of the atmosphere in the region. The climate in this area shows large variability (Garreaud 2009; Garreaud et al. 2009), depending on altitude, location, and proximity to the sea and to the Amazon region.
AfFiliations: Muñoz-Centro de Modelado Científico, La Universidad del Zulia, Maracaibo, Venezuela, and Centro Internacional para la Investigación del Fenómeno El Niño, Guayaquil, Ecuador; LóPEZ-Agencia Estatal de Meteorología (AEMET), Madrid, Spain; VelÁsquez And Monterrey-Servicio de Meteorología de la Fuerza Aérea Venezolana (SEMETFAV), Maracay, Venezuela; LEÓN AND RUIz-Instituto de Hidrología, Meteorología y Estudios Ambientales (IDEAM), Bagotá, Colombia; Recalde, Cadena, and MejíA-Instituto Nacional de Meteorología e Hidrología (INAMHI), Guayaquil, Ecuador; PARedes, Bazo, AND ReYES-Servicio Nacional de Meteorología e Hidrología (SENAMHI), Lima, Peru; Carrasco and Castellón-Servicio Nacional de Meteorología e Hidrología (SENAMHI), La Paz, Bolivia;
The ground observational network of the six Andean countries is neither homogeneously distributed nor dense enough, and only a few national weather services (NWSs) have weather radars or radiosounding stations working on a regular basis. Satellite products are the most common and useful tools for nowcasting tasks in the region, while the Global Forecast System (GFS; Kalnay et al. 1990) is the most frequently used model for operational forecasting.

Until 2006, efforts for building a regional and collaborative climate watch system for the Andean countries have been scarce. In 2007, Centro Internacional para la Investigación del Fenómeno "El Niño" (CIIFEN) received the approval and funding support from the Inter-American Development Bank

Villarroel and Quintana-Dirección Meteorológica de Chile, Santiago, Chile; URDANETA-Centro de Modelado Científico, La Universidad del Zulia, Maracaibo, Venezuela CORRESPONDING AUTHOR: Ángel G. Muñoz, Centro de Modelado Científico, La Universidad del Zulia, Maracaibo 4004, Venezuela

E-mail: agmunoz@cmc.org.ve

The abstract for this article can be found in this issue, following the table of contents.

DOI:10.1175/2010BAMS2958.1

In final form 27 May 2010

(02010 American Meteorological Society 
(IDB) for the execution of a regional project entitled "Climate information applied to agricultural risk management in the Andean countries" (CIIFEN 2007). Its implementation provided a valuable tool to the agricultural sector and, at the same time, allowed for the development of a common methodology for the elaboration of agroclimatic risk maps on selected crops. An important component of the project involved capacity building of the participant NWSs on both a probabilistic and a dynamic downscaling basis. The Centro de Modelado Científico (CMC) signed a collaborative agreement with CIIFEN that included support for the development of the necessary methodology, computational models, infrastructure, and training for running dynamical downscaling models, as well as an experimental seasonal forecast system for the involved countries, in particular, running a general circulation model (GCM) in order to provide the necessary boundary conditions. This collaboration established the basis of the Observatorio Andino (OA) in 2008.

The OA main goal is to provide, in addition to the existing tools in each country, a collaborative network that ultimately increases the efficiency of the decision-making processes, especially in terms of getting more accurate forecasts and exchanging experiences on data, information, and scientific products, all of which is done with a standardized methodology and a Web-sharing service.

This paper is organized as follows: "The Observatorio Andino and its products" introduces the members of the OA and its products, "General forecast methodology and verification" describes the general forecast and verification methodologies, "Present difficulties and strategies" pinpoints various difficulties evidenced in the regional project, and "Concluding remarks" discusses the achievements and future perspectives of the regional initiative.

THE OBSERVATORIO ANDINO AND ITS PRODUCTS. The aim of the OA is to monitor and forecast key environmental variables and develop accurate forecasts based on different scientific tools, in order to help decision makers improve risk management and set up efficient early warning systems. The OA provides several model outputs for meteorological, seasonal, and hydrological forecasts, 5-day high-resolution oceanographic prediction for the eastern Pacific, droughts, fire and flood indices, ecosystem dynamics (like duckweed/algae occurrence in Maracaibo Lake), and climate and health (e.g., regarding malaria) applications, among other products.
Currently, CMC and CIIFEN provide the logistic and scientific coordination of the OA. Six NWSs and several universities and research centers, including the International Research Institute for Climate and Society (IRI) of Columbia University (New York), San Andrés Major University (Bolivia), Catholic University (Colombia), and Chile University (Chile), actively participate in the initiative. The NWSs are in charge of validating and verifying the OA products and their use in each national early warning system, whereas universities and research centers produce scientific tools, methodologies, and training modules that are implemented by the NWSs.

The OA is organized as interconnected working groups (WGs) or axes, namely, meteorology; climatology; hydrology; air quality; climate and health; and climate change. Each WG has its own procedures and products, but all of them exchange information and results with other axes and countries if necessary.

Information on the OA's philosophy and objectives, its members, and useful step-by-step instructions for installing, configuring, and executing the available models can be found online (http://mediawiki.cmc. org.ve; in Spanish as well as English). It also describes several methodologies, such as computing models climatologies and anomalies, executing seasonal forecasting, performing objective analysis, and using geographical information system (GIS) interfaces and verification processes, to mention just a few.

Advances and difficulties are shared and discussed through e-mail lists and videoconferences using the open-source software Enabling Virtual Organizations (EVO). The purpose of the videoconferences is to discuss the ongoing projects, products, and new methodologies, and to provide special assistance on models and several other technical issues.

\section{GENERAL FORECAST METHODOLOGY} AND VERIFICATION. Still in an experimental stage, the Observatorio Andino follows a threelevel hierarchical model execution flux, with the same approach for both short-term and seasonal products.

Level I involves global-scale analysis and/or GCM outputs that are used as first-guess or boundary/initial conditions for downscaling models (level II). The downscaling products, in turn, provide the necessary information for level III, which consists of microscale and/or tailored applications, such as hydrological forecasts or climate and health early warning systems.

A very important issue is the forecasting verification. Forecasts should guarantee consistency, quality, and value (Mason and Stephenson 2008) if they are 
to help decision makers. However, even when the OA internally employs different standard metrics for the measurement of different forecast attributes, they are, in general, not well understood by the final user or decision maker. Thus, for validation and verification methodologies, ${ }^{1}$ an additional approach that generates easily and intuitively understandable spatial maps to end users has been provided to all OA partners.

In order to facilitate the validation process, a spatial map for each time slice of interest (daily, monthly, and seasonal), involving the differences and/or the anomaly correlations between model output and observations, is generated. For this purpose, the station data are objectively analyzed using the Cressman (1959) iterative scheme according to the model resolution and considering the scheme's elevation corrections due to the terrain complexity (accordingly, the final fields recognize the Andes presence). Thus, the differences or anomaly correlations are calculated over the gridded fields. Even when some problems occur with the objective analysis resulting from the low station density in the Andes region, in general the procedure results are satisfactory and, overall, both useful and well understood by decision makers.

Another simple approach consists of constructing time series from the variables of interest, which include the local data (station) and the model output, after a bilinear interpolation to the station coordinates has been done for the latter. In general, this kind of interpolation provides good results in most of the cases. However, because of the complex terrain, other approaches using digital elevation models are in the course of experimentation.

The models running in the OA are depicted in Table 1. The main execution procedures are automated, as well as the postprocessing schemes. In the next subsections, a brief description of the general procedures is presented.

Dynamical weather forecast. At present, the OA provides 72 -h weather forecasts on a daily basis using the following high-resolution downscaling models: the fifth-generation Pennsylvania State University (PSU)National Center for Atmospheric Research (NCAR)

${ }^{1}$ Here we follow the convention that relates validation with the models per se, while verification is done for forecasts. At the $\mathrm{OA}$, the NWSs are the institutions in charge of verifying products, while any institution could validate model outputs.

\begin{tabular}{|c|c|c|c|c|}
\hline $\begin{array}{l}\text { Model/index } \\
\text { (version) }\end{array}$ & $\begin{array}{c}\text { Hierarchy level/ } \\
\text { type }\end{array}$ & Executed by & $\begin{array}{c}\text { Initial/boundary } \\
\text { conditions }\end{array}$ & Domain \\
\hline GFS & I/daily & NOAA & GDAS & Global \\
\hline $\begin{array}{l}\text { CAM OA } \\
(\text { CAM 3.I) }\end{array}$ & I/seasonal & CMC & $\begin{array}{l}\text { P_SST, cfs_SST, and } \\
\text { ca_SST(two tiered) }\end{array}$ & Global \\
\hline $\begin{array}{c}\text { WRF } \\
\text { (WRF version 3.I) }\end{array}$ & II/daily & $\begin{array}{l}\text { CMC/Andean NWSs } \\
(\text { six })\end{array}$ & GFS, local data & $\begin{array}{c}\text { South America/ } \\
\text { country }\end{array}$ \\
\hline $\begin{array}{c}\text { MM5 } \\
\text { (MM5 version 3.7) }\end{array}$ & II/daily & $\begin{array}{l}\text { CMC/Andean NWSs } \\
(\text { six })\end{array}$ & GFS, local data & $\begin{array}{c}\text { South America/ } \\
\text { country }\end{array}$ \\
\hline $\begin{array}{c}\text { CWRF } \\
\text { (WRF version 2.2) }\end{array}$ & II/seasonal & $\begin{array}{l}\text { CMC/Andean NWSs } \\
(\text { six })\end{array}$ & CAM OA & $\begin{array}{c}\text { South America/ } \\
\text { country }\end{array}$ \\
\hline $\begin{array}{c}\text { CMM5 } \\
\text { (MM5 version 3.7) }\end{array}$ & II/seasonal & $\begin{array}{l}\text { CMC/Andean NWSs } \\
(\text { six })\end{array}$ & CAM OA & $\begin{array}{c}\text { South America/ } \\
\text { country }\end{array}$ \\
\hline $\begin{array}{c}\text { CPT } \\
\text { (CPT version 9.03) }\end{array}$ & II/seasonal & Andean NWS (six) & Various from IRIDL & Andean countries \\
\hline $\begin{array}{c}\text { ROMS } \\
\text { (ROMS-AGRIF) }\end{array}$ & II/daily & CMC & ECCO and GFS & Eastern Pacific \\
\hline $\begin{array}{c}\text { VIC } \\
(\text { VIC version 4.0.6) }\end{array}$ & III/seasonal & CMC and INAMHI & CWRF and CMM5 & Country \\
\hline $\begin{array}{l}\text { Droughts, floods, and } \\
\text { fires }\end{array}$ & III/daily/seasonal & CMC & CWRF and CMM5 & South America \\
\hline CAVEL & III/seasonal & CMC & MODIS & State/province \\
\hline $\begin{array}{c}\text { Malaria } \\
\text { (McDonald) }\end{array}$ & III/seasonal & CMC and INAMHI & CWRF & $\begin{array}{c}\text { South America/ } \\
\text { Ecuador }\end{array}$ \\
\hline
\end{tabular}


Mesoscale Model (MM5; Michalakes 2000) and the Weather Research and Forecasting model (WRF; Skamarock et al. 2005). The GFS (Kalnay et al. 1990) 3-hourly outputs and assimilation of surface synoptic observations (SYNOP), aviation routine weather report (METAR), and upper-air sounding (TEMP) reports are used as initial conditions. Each country has determined the best set of parameterizations for the models, which typically run at $30-\mathrm{km}$ or higher resolution.

The model outputs are considered valuable additional tools for the forecasting processes in countries where the Andes Mountain chain provides complex disturbances that GFS and other global models frequently cannot resolve because they are lacking enough skill.

Dynamical seasonal forecast. The NCAR Community Atmospheric Model, version 3.1 (CAM3.1; Collins et al. 2006) has been configured at T42L26 resolution in $\mathrm{CMC}$ for Atmospheric Model Intercomparison Project (AMIP)-style runs with greenhouse gas (GHG) monthly variability from 1966 to present. The first five years have been discarded for spinup reasons. The selected climatology corresponds to the 1971-2000 period. This particular configuration is termed "CAM OA" herein.

The present seasonal forecast methodology is sketched in Fig. 1. On a monthly basis, the CAM OA runs six ensemble members, where, as tier 1, i) two of them follow the persistent SST " $e$-folding" methodology (p_sst; see, e.g., Shuhua et al. 2008), ii) two members use the SST forecast of the Climate Forecast System (CFS) model (cfs_sst; Saha et al. 2006), and iii) two realizations are obtained following the constructed analog (ca_sst; Van den Dool 1994) methodology. For all members the lead's monthly ice fraction coverage is described by the climatological values. For each member's output, the necessary initial and boundary conditions are extracted and written in the special (intermediate) format requested by the climatic versions of MM5 (CMM5) and WRF (CWRF), and are then available for the Andean NWSs through the OA portal (online at http://ole2. org), which has been totally built with open-source resources by CMC developers.

Each NWS downloads the needed files to execute the models in its own computational infrastructures, and, since January 2010, uses two different sets of physical parameterizations per model. Thus, a multiparametric multimodel ensemble is produced for each country, and then uploaded to the OA portal for its publication after internal filters and discussion. In Fig. 2 an OA's seasonal precipitation anomaly map is presented for all of South America, with the corresponding observed rainfall anomaly for comparison.

These products are also used in each NWS for the generation of agricultural risk maps and other products and tools for decision makers.

Statistical seasonal forecast. The IRI's Climate Predictability Tool (CPT; http://iri.columbia.edu/outreach/ software) is used to obtain probabilistic seasonal forecasts of mean, maximum, and minimum temperature, as well as accumulated precipitation in the six Andean countries. Before this tool was implemented, the NWSs used to draw by hand on a map the forecasts based on the available information and subjective procedures. After CPT was introduced in the region in 2005/06 (a CIIFENIRI collaboration), the main methodologies followed in the region consisted of a canonical correlation analysis or a principal component analysis, with the former still being the most frequently used today. The technical details are discussed by Mason and Baddour (2008). The usual predictors, downloaded every month from the IRI Data Library, are the observed SST and, for both 850and $500-\mathrm{mb}$ levels, the geopotential 
height, zonal and meridional wind velocities, potential velocity, and specific humidity. Local station data for precipitation and temperature are included as predictands. The forecasts are provided in monthly, bimonthly, and seasonal formats, and each country dataset involves no fewer than $35 \mathrm{yr}$ of data. This process is done by the corresponding NWS through a regionalization procedure of its country, taking into account the principal component analysis and the forecaster's experience.

The forecast probabilities are first distributed as a nationwide spatial map by the NWSs and then sent to CIIFEN for integration with all of the products in the regionwide maps. The final products appear monthly as temperature and rainfall anomalies charts in CIIFEN's bulletin (http://www.ciifen-int.org).

Oceanographic high-resolution forecast. The Regional Oceanic Modeling System-Adaptive Grid Refinement

\section{PRECIPITATION ANOMALY JFM 2010}

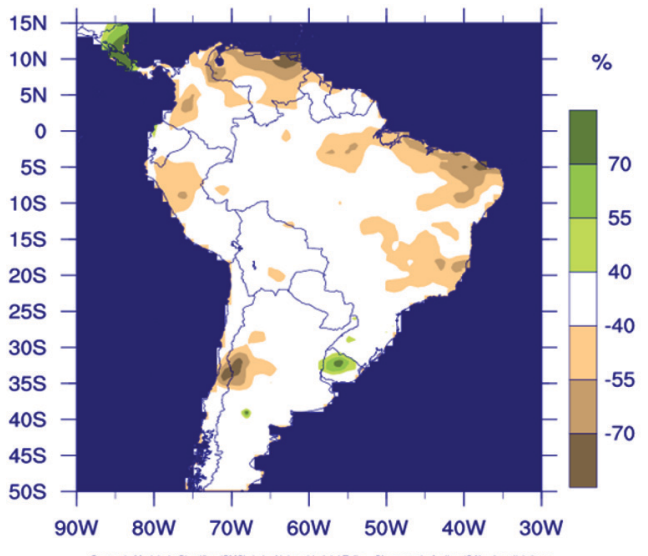

OBSERVED ANOMALY. PRECIPITATION JFM 2010

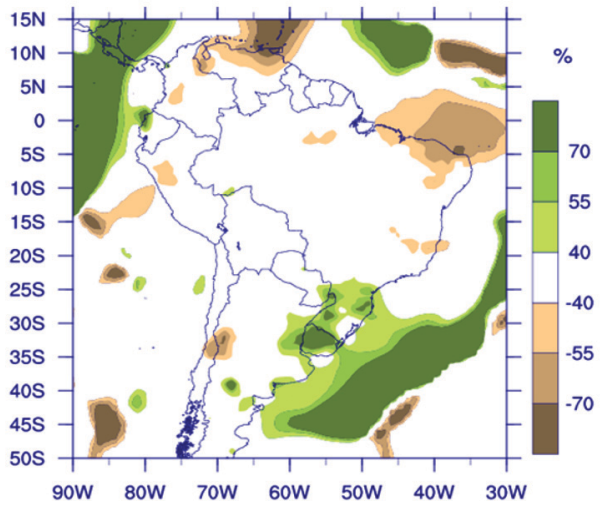

FIG. 2. South American seasonal anomaly precipitation (top) forecast and (bottom) observations for the period of Jan-Mar 2010. The forecast (CWRF model at 30-km resolution) corresponds to the ensemble downscaling product with bias correction. The observed field data are from the Climate Prediction Center. in FORTRAN (ROMS-AGRIF; Penven et al. 2007) has been configured for a computational domain in the eastern Pacific. At present, the boundary and initial conditions are provided by the Estimating the Circulation and Climate of the Ocean (ECCO) Consortium (Stammer et al. 1999) and the GFS (Kalnay et al. 1990). The OA runs daily ROMS for a 5 -day high-resolution $(30 \mathrm{~km})$ forecast, sharing products such as SST, surface salinity, vertical velocities (upwelling and downwelling), and marine currents online. As an example, a vertical velocity map is shown in Fig. 3. This kind of product is very useful for fisheries maps, providing approximate locations of nutrient-rich regions resulting from upwelling processes.

This OA's component has been developed by CMC in collaboration with the Comision Permanente del Pacífico Sur (CPPS) in order to set up the same methodology developed by the NWSs but, in this case, for the marine and coastal services of Colombia, Ecuador, Peru, and Chile.

Dynamical hydrological forecast. The dynamical hydrological forecast (level III) process is done in the OA by coupling the Noah land surface model (Schaake et al. 1996) with the level II models, or directly using

\section{Omega Date: $09 / 05 / 2010$}

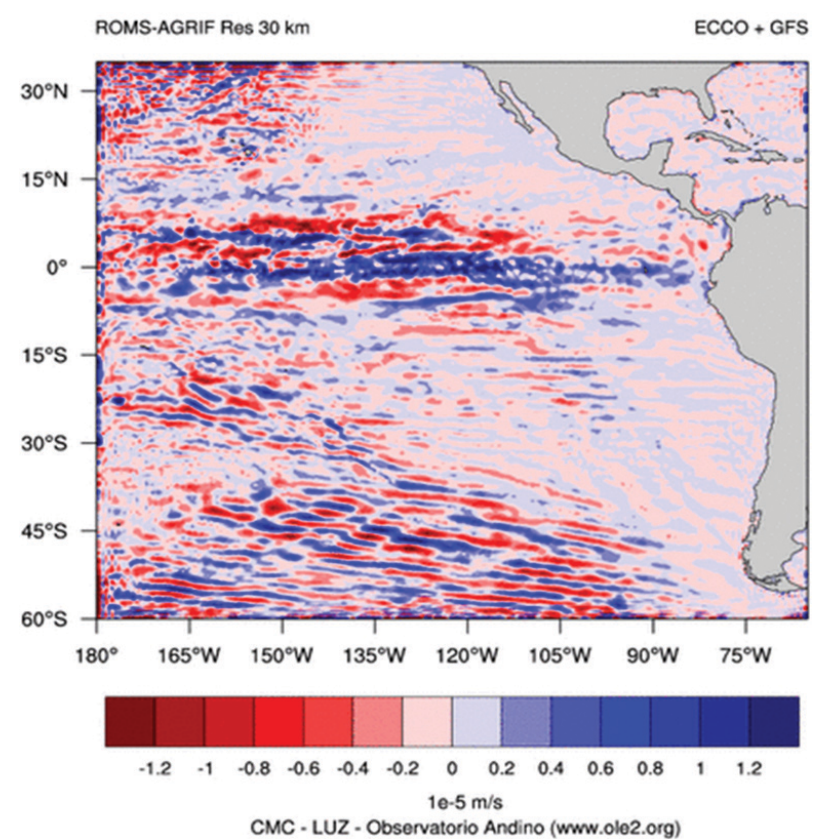

FIG. 3. Upwelling (vertical velocity) map for the eastern Pacific using ROMS (see "Oceanographic highresolution forecast"). 
the latter's forecasted precipitation, temperature, and wind outputs into the Variable Infiltration Capacity (VIC) model of Liang et al. (1994; Liang and Xie 2001). VIC is a macroscale (typical cell resolution $>1 \mathrm{~km}$ ), semidistributed hydrologic model that solves full water and energy balances. In the OA, the VIC is specifically configured for each basin of interest (the resolution depends on the selected basin) with the corresponding soil and vegetation type data.

For both procedures (coupled land surface models or the uncoupled VIC model), a bias-correcting calibration procedure is applied to the raw output using historical local streamflow data as reference (see Fig. 4 for one example of an Ecuadorian basin).

After the calibration stage, the final outputs can be considered as a main tool for the corresponding early warning system in the involved countries.

Other applications. Other applications include products related to droughts, floods, fires, and ecosystem dynamics. In the case of droughts, Palmer (1965, 1968) indices are employed, while a composite map between runoff and the hydrologic capacity of model cells is used to forecast possible floods. Likewise, the Chandler et al. (1983) index is employed as a measure of joint probability of fire occurrence and propagation.

Climate and health applications are focused mainly on malaria seasonal predictability for northwestern

BABAHOYO. MONTHLY. 2002-2004

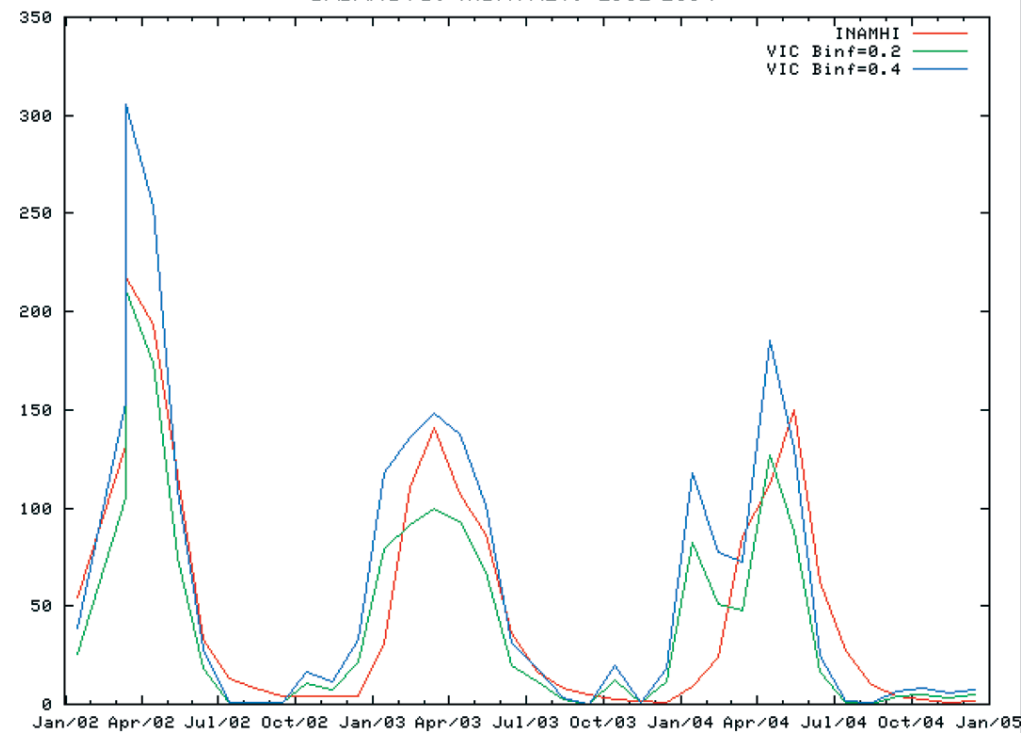

FIG. 4. An example of observed and simulated (VIC) monthly streamflows $\left(\mathrm{m}^{3} \mathrm{~s}^{-1}\right)$ over the period from Jan 2002 through Dec 2004 for the Babahoyo basin in Ecuador (see “Dynamical hydrological forecast”). Observed data appear in red. Simulations correspond to two different values of the VIC infiltration parameter (Binf).
South America using the McDonald (1957) model. Given the necessary entomological and epidemiological parameters, the OA's high-resolution outputs provide the climate information that is needed to run this epidemiological tool.

Finally, a new framework is related to ecosystem dynamics, especially Lemna (duckweed) population dynamics. In 2004 an important duckweed bloom took place in Maracaibo Lake (Tapias 2010), South America's largest lake, bringing economic (e.g., tolls on fisheries) and health-related (e.g., necrotic Lemna at lake shores produce an increase in disease occurrence) problems to human populations in those coastal zones. Recently, the CMC provided an application known as CAVEL (Tapias 2010) that makes use of Moderate Resolution Imaging Spectroradiometer (MODIS) VIS and IR data (Barnes and Salomonson 2002) for providing normalized difference vegetation index (NDVI) maps and time series of total surface coverage. As an example, Fig. 5 shows a composite of Lemna images in visible and NDVI.

\section{PRESENT DIFFICULTIES AND STRATEGIES.}

Although several difficulties arose in the process of the OA development, the efforts and decisions of the six NWSs were of fundamental importance for promoting the OA initiative.

The statistical and dynamic modeling training sessions, organized by CIIFEN in the framework of the IDB project, have been a crucial component for providing the necessary human resources in the Andean region. These training processes have been composed by three workshops. The first of them, regarding statistical modeling and CPT, was held in Maracay, Venezuela, in October 2007. The other two workshops, focused on dynamic downscaling model installation, execution, and postprocessing, were held in Lima, Peru, in November 2007 and in Guayaquil, Ecuador, in June 2008. The OA has made extensive use of its wiki, webinars, and videoconferences for standardizing the methodologies, updating the different scripts and products, discussing the regional results, and solving technical issues.

Despite the advances made since its creation, the OA does not have its own funding and survives thanks to the support given by its members. 
Each NWS or institution provides available data, computers and communications, and human resources, but there is clearly a need for additional resources. The lack of personnel has forced the OA to automate most of the tasks, while the scarcity of computers dedicated to modeling has become an important motivation for sharing the resources of all of the institutions in a new project called ANDESGrid (2010). Certainly, the OA has transformed some disadvantages into advantages. However, funding is still needed to guarantee the survival of this regional collaboration, mainly to prepare more human resources, facilitate the exchange of experiences through regional meetings, and buy more computing and storage units.

Even when political differences between countries have not been an important barrier, more attention from local governments is definitely needed for supporting this initiative. For instance, in Venezuela there has been an important funding reduction for almost every public university, which severely affected the evolution of this project.

The perspectives of the OA not only aim to ensure local support but also build new partnerships with international institutions that may strengthen and extend the actual lines of action and products, as well as the related researching and development activities.

CONCLUDING REMARKS. In the last two years, many efforts have been directed to providing several scientific environmental tools for decision makers by both operative and research institutions in the Andean countries.

Of the OA's main achievements in this period, the most important is the enhancement of the NWSs' human resources by means of continuous technical support for forecast, modeling, verification, objective analysis, and many other issues, all of which is done in their native language. Human resources have considerably increased their expertise on dynamical and statistical modeling, data processing and formats, model assimilation procedures, efficient use (and sharing) of computational resources, and even understanding the dynamical systems that modulate the climate on their countries, but with a more regional perspective and understanding than before.

The project has also succeeded in standardizing forecasts, data formats, and verification/validation methodologies in the Andean countries, providing common models, tools, and procedures that are used on a daily basis from Venezuela to Chile. The key tool has been the wiki, which contains all of the needed steps for each task, which by itself is one of the most important elements for ensuring the long-term continuity of the OA. Even though it is a technical reference, today it counts several thousand visits, not all of which are only from the involved Andean countries.

With around 700 visits each month in the last two years, the OA product Web site is providing different tools in one place to help decision makers plan future actions and improve risk management in the Andean countries.

ACKNOWLEDGMENTS. The Observatorio Andino acknowledges the invaluable contribution of several people (Estatio Gutiérrez, Rainer Schmitz, Daniel Ruiz, Marcos Andrade, Luis Blacutt, Mercy Borbor, Bryan Jordan, Joaquín Díaz, Xandre Chourio, Siulluz Reverol, Eugenio Tapias, and 
Euselyne Sebrian), as well as various institutions (CMC, CIIFEN, SEMETFAV, IDEAM, INAMHI, SENAMHI Perú, SENAMHI Bolivia, DMC, IDB, FUNDACITE ZULIA, IVIC, AEMET, and CPPS), that have been key actors for keeping the OA Project alive. The IRI crew deserves special thanks (Walter Baethgen, Lisa Goddard, Simon Mason, David DeWitt, Liqiang Sun, Tony Barnston, Gilma Mantilla, Esteban Andrade, and others) for their scientific support, suggestions, and training. The authors are grateful to Brant Liebmann and three anonymous referees for their useful comments on the original version of the manuscript.

\section{REFERENCES}

Barnes, W. L., and V. V. Salomonson, 1992: A global imaging spectroradiometer for the Earth Observing System. Critical Review, Optical Technologies for Aerospace Sensing, Vol. CR 47, 1-23.

Chandler, C., P. Cheney, P. Thomas, L. Trabaud, and D. Williams, 1983: Forest Fire Behavior and Effects. Vol. I, Fire in Forestry, John Wiley \& Sons, 450 pp.

CIIFEN, 2007: Climate information applied to agricultural risk management in the Andean countries. ATN/OC-10064-RG Project, 40 pp.

Collins, W. D., and Coauthors, 2006: The formulation and atmospheric simulation of the Community Atmosphere Model Version 3 (CAM3). J. Climate, 19, 2144-2161.

Cressman, G. P., 1959: An operational objective analysis system. Mon. Wea. Rev., 87, 367-374.

Garreaud, R. D., 2009: The Andes climate and weather. Adv. Geosci., 7, 1-9.

_-, M. Vuille, R. Compagnucci, and J. Marengo, 2009: Present-day South American climate. Palaeogeogr. Palaeoclimatol. Palaeogeogr., 281, 180-195, doi:10.1016/j.palaeo.2007.10.032.

Kalnay, E., M. Kanamitsu, and W. E. Baker, 1990: Global numerical weather prediction at the National Meteorological Center. Bull. Amer. Meteor. Soc., 71, 1410-1428.

Liang, X., and Z. Xie, 2001: A new surface runoff parameterization with subgrid-scale soil heterogeneity for land surface models. Adv. Water Resour., 24 (9-10), 1173-1193.

— , D. P. Lettenmaier, E. F. Wood, and S. J. Burges, 1994: A simple hydrologically based model of land surface water and energy fluxes for GSMs. J. Geophys. Res., 99 (D7), 14415-14428.

MacDonald, G., 1957: The Epidemiology and Control of Malaria. Oxford University Press, $201 \mathrm{pp}$.

Mason, S., and O. Baddour, 2008: Statistical modelling. Seasonal Climate: Forecasting and Managing Risk, A. Troccoli et al., Eds., Springer, 163-201.
— whether seasonal climate forecasts are any good? Seasonal Climate: Forecasting and Managing Risk, A. Troccoli et al., Eds., Springer, 259-289.

Michalakes, J., 2000: The same-source parallel MM5. J. Sci. Comput., 8, 5-12.

Muñoz, Á. G., X. Chourio, S. Reverol, A. Urdaneta, and C. Díaz, 2010: ANDESGRID: A Grid Infrastructure for Geosciences in the Andean countries. Proc. Latin-American Conf. on High Performance Computing, Gramado, Brazil, Bull, Hewlett-Packard, Intel Corporation, Microsoft, Silicon Graphics International, 9-14.

Palmer, W. C., 1965: Meteorological drought. U.S. Weather Bureau Research Paper 45, 65 pp. [Available online at http://lwf.ncdc.noaa.gov/temp-and-precip/ drought/docs/palmer.pdf.]

— 1968 : Keeping track of crop moisture conditions nationwide: The new crop moisture index. Weatherwise, 21, 156-161.

Penven, P., P. Marchesiello, L. Debreu, and J. Lefevre, 2007: Software tools for pre- and post-processing of oceanic regional simulations. Environ. Modell. Software, 23, 660-662.

Saha, S., and Coauthors, 2006 : The NCEP Climate Forecast System. J. Climate, 19, 3483-3517.

Schaake, J. C., V. I. Koren, Q.-Y. Duan, K. Mitchell, and F. Chen, 1996: Simple water balance model for estimating runoff at different spatial and temporal scales. J. Geophys. Res., 101 (D3), 7461-7475.

Shuhua, L., L. Goddard, and D. G. Dewitt, 2008: Predictive skill of AGCM seasonal climate forecasts subject to different SST prediction methodologies. J. Climate, 21, 2169-2186.

Skamarock, W. C., J. B. Klemp, J. Dudhia, D. O. Gill, D. M. Barker, W. Wang, and J. G. Powers, 2005: A description of the Advanced Research WRF Version 2. NCAR Tech. Note NCAR/TN-468+STR, 88 pp. [Available online at www.mmm.ucar.edu/wrf/users/ docs/arw_v2.pdf.]

Stammer, D., and Coauthors, 1999: The consortium for estimating the circulation and climate of the ocean (ECCO)-Science goals and task plan. ECCO Consortium Rep. 1, 24 pp.

Tapias, E., 2010: CAVEL: Sistema para el reconocimiento y análisis digital de imágenes de Lemna en el Lago de Maracaibo basado en fotografias satelitales (Venezuelan Open Source System for Lemna Evolution in Maracaibo Lake). B.A. thesis, Facultad de Ciencias, La Universidad del Zulia, 104 pp. [Available online at http://cmc.org.ve/descargas/Tapias2010.pdf.]

Van den Dool, H., 1994: Searching for analogues, how long must we wait? Tellus, 46A, 314-324. 